\title{
Intra-seasonal variation in the velocity field of the northeastern South China Sea
}

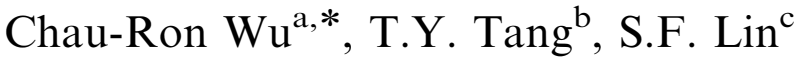 \\ ${ }^{a}$ Department of Earth Sciences, National Taiwan Normal University, Taipei, Taiwan, ROC \\ ${ }^{\mathrm{b}}$ Institute of Oceanography, National Taiwan University, Taipei, Taiwan, ROC \\ ${ }^{\mathrm{c}}$ Energy \& Resources Laboratories, Industrial Technology Research Institute, Hsinchu, Taiwan, ROC
}

Available online 26 September 2005

\begin{abstract}
Two subsurface Acoustic Doppler Current Profilers (ADCP) were deployed in the northeastern South China Sea to study the circulation structure in the area as well as the path and process of the Kuroshio intrusion. The $48 \mathrm{~h}$ low-pass filtered data, for the first time, reveal significant intra-seasonal variations in the velocity field. Flow is alternately cyclonic or anticyclonic even within a single month. Local wind forcing dominated by monsoon winds fails to address the phenomena. The present study suggests that intruding current patterns are likely triggered by the strong wind stress curls. Strong negative wind stress curls off the southern tip of Taiwan introduce negative vorticity to form anticyclonic circulation in the intruding current. With diminishing wind stress curls, the intruding current weakens, forming a cyclonic circulation pattern.
\end{abstract}

(C) 2005 Elsevier Ltd. All rights reserved.

Keywords: Intra-seasonal variation; South China Sea; Eddies; Wind stress curl

\section{Introduction}

The circulation structure in the northern South China Sea is complicated because of the complex topography and forcing by seasonally reversing monsoons. In addition, this region is the confluence of currents in the northern South China Sea, the Taiwan Strait and the Kuroshio. The Kuroshio is the strongest current in the vicinity of the Luzon Strait.

The Pacific western boundary current, the Kuroshio, flows northward east of Luzon and

\footnotetext{
*Corresponding author. Tel.: 886229347120 ex.16; fax: 886229333315 .

E-mail address: cwu@cc.ntnu.edu.tw (C.-R. Wu).
}

Taiwan (Nitani, 1972). Similar to the Loop Current in the Gulf of Mexico, the Kuroshio water has been reported to intrude into the Luzon Strait, a deep gap in the western boundary (Nitani, 1972; Shaw, 1991). Since the Luzon Strait is the only deep passage of the South China Sea, the intrusion of water from the Kuroshio is important to the salt budget in the basin. Seasonal variations of Kuroshio intrusion based on water mass distribution have been reported extensively in a wealth of the existing literature (e.g. Wyrtki, 1961; Nitani, 1972; Shaw, 1991). Although the intrusion of waters from the Kuroshio to the northeastern South China Sea is known, the circulation pattern associated with the intrusion is unclear. Wang and Chern (1987) suggested that intrusion is in the form of 
an anticyclonic (clockwise) eddy at the onset of the northeast monsoon. Shaw (1989) suggested that the intruding water is passively advected by the basinwide cyclonic circulation in the northern South China Sea in winter. Recent moored current-meter and ship-board ADCP data showed that westward flow persisted in the region southwest of Taiwan year round (Liang et al., 2003).

In this study, data from two mooring stations in the region were examined to study the circulation pattern. The data consist of flow velocity and water properties. Thus, the effect of the Kuroshio intrusion can be inferred. The blended QSCAT/NCEP (NASA Quick Scatterometer/National Centers for Environmental Prediction) wind stress fields at a resolution of $0.5^{\circ} \times 0.5^{\circ}$ (Milliff et al., 1999) were used to infer the driving mechanisms.

\section{Mooring data}

Two subsurface moorings ( $\mathrm{W}$ and $\mathrm{E}$ ) were deployed in continental margin southwest of Taiwan from October 2000 to April 2001. Fig. 1 shows the mooring locations and the surrounding bathymetry. Each mooring includes an upwardlooking, $150 \mathrm{kHz}$, self-contained ADCP mounted on a $45^{\prime \prime}$ diameter spherical syntactic foam buoy and a SEACAT conductivity-temperature-depth (CTD) mounted $5 \mathrm{~m}$ beneath the ADCP. The water depths at $\mathrm{W}$ and $\mathrm{E}$ are 1014 and $968 \mathrm{~m}$, respectively. Table 1 lists the locations and local water depths for each mooring, the depths of instruments, the duration of deployments, and the vertical range of current profile measured by the ADCP. The bin length of ADCP was $8 \mathrm{~m}$. The hourly current velocity was averaged over 240 pings for broadband ADCP. The standard deviations of velocity were $1.2 \mathrm{~cm} \mathrm{~s}^{-1}$. Errors caused by vertical excursion of the instrument and sound speed variation in the ADCP data were corrected by the temperature and depth obtained by CTD. The data were also adjusted for local magnetic deviation. The velocity in the vertical profile was then linearly interpolated and resampled at $10 \mathrm{~m}$ intervals. The time series of current velocity discussed in the following sections were low-pass filtered to remove the fluctuations for frequencies higher than 0.5 cycles per day.

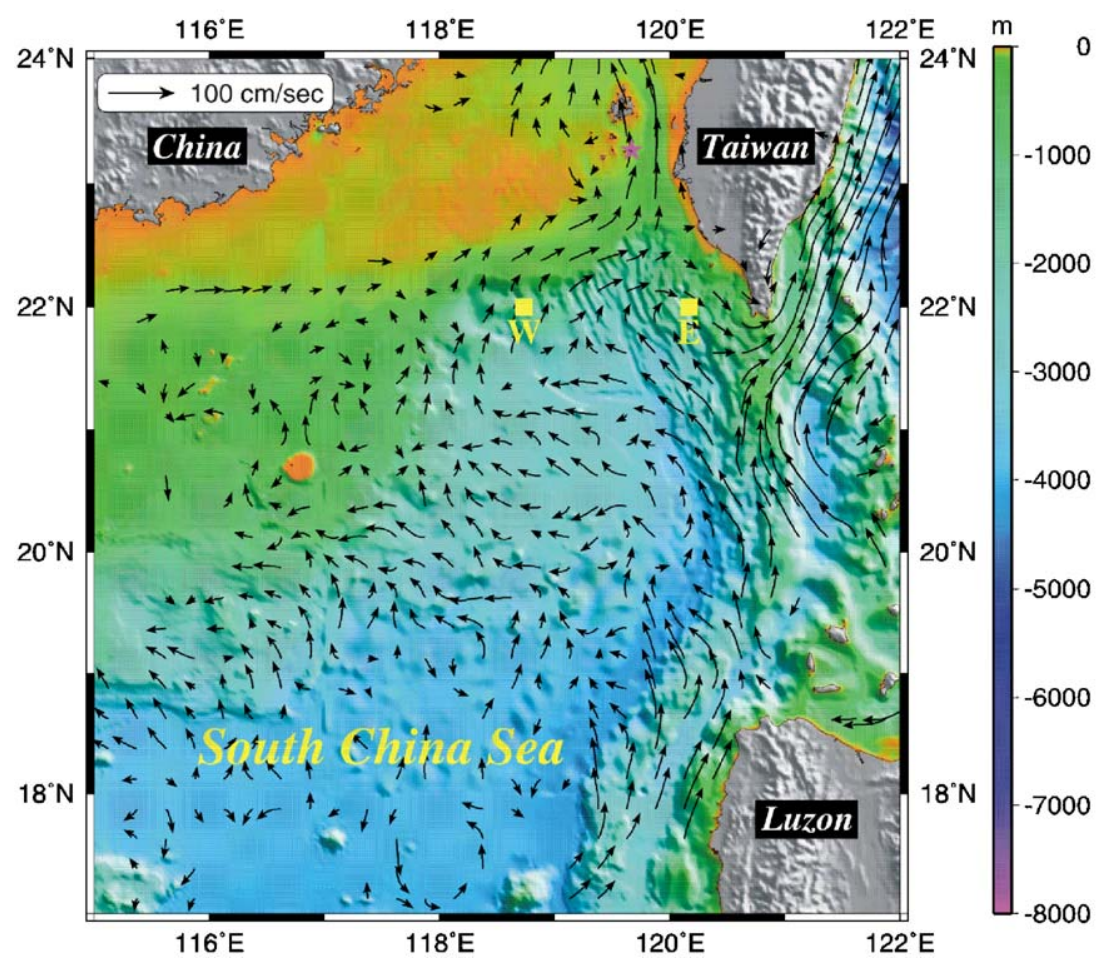

Fig. 1. The study area with locations of mooring stations (squares) and Tung-Chi Island (asterisk). Current distribution at $30 \mathrm{~m}$ is adopted from Liang et al. (2003). 
Table 1

Mooring locations; water, ADCP and CTD depths; durations; and data distribution depths (interval of $10 \mathrm{~m}$ ) at W and E, respectively

\begin{tabular}{llllllll}
\hline Station & Longitude & Latitude & $\begin{array}{l}\text { Water } \\
\text { depth }(\mathrm{m})\end{array}$ & $\begin{array}{l}\text { ADCP } \\
\text { depth }(\mathrm{m})\end{array}$ & $\begin{array}{l}\text { CTD depth } \\
(\mathrm{m})\end{array}$ & Duration & $\begin{array}{l}\text { Measurement } \\
\text { range }(\mathrm{m})\end{array}$ \\
\hline $\mathrm{W}$ & $118^{\circ} 44^{\prime} \mathrm{E}$ & $22^{\circ} \mathrm{N}$ & 1014 & 160 & 165 & $2000 / 10 / 13-2001 / 04 / 18$ \\
$\mathrm{E}$ & $120^{\circ} 10^{\prime} \mathrm{E}$ & $22^{\circ} \mathrm{N}$ & 968 & 202 & 207 & $2000 / 10 / 04-2001 / 04 / 18$ & $20-180$ \\
\hline
\end{tabular}

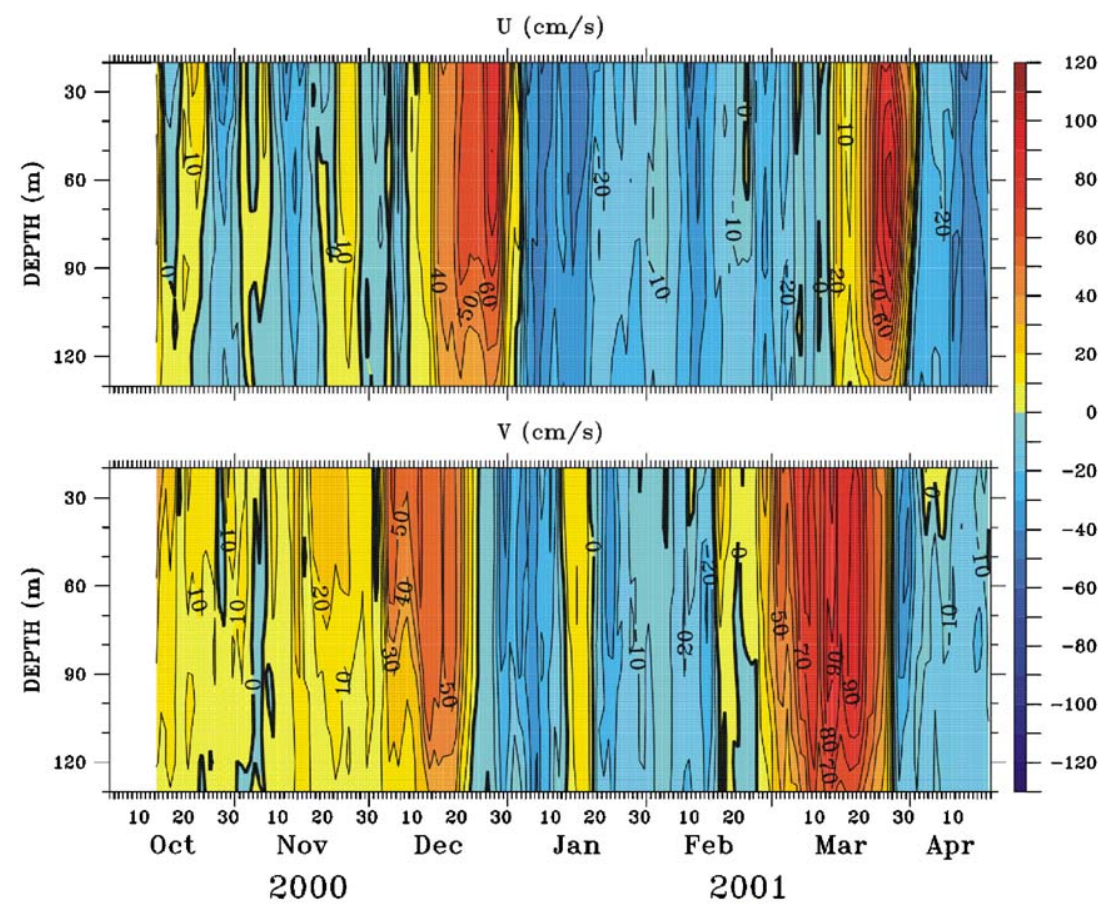

Fig. 2. Vertical sections of 48 -hr low-pass current velocity observed at W. Contour interval is $10 \mathrm{~cm} \mathrm{~s}^{-1}$.

\section{Results and discussion}

\subsection{Low-pass filtered velocity}

Fig. 2 shows the 48-h low-pass filtered eastward $(U)$ and northward $(V)$ velocity components at $\mathrm{W}$. In general, the flow is barotropic in the upper $120 \mathrm{~m}$ with a slight decrease in magnitude. Both $U$ and $V$ show significant intra-seasonal variations. In November 2000, $U$ is weak and alternates directions between west and east. Flow strengthens and turns eastward in December, reaching its maximum strength at the end of December. At the beginning of January, the eastward current suddenly reverses the direction toward west. The westward persists until mid-March. Another burst of strong eastward flow appears afterward and reaches its maximum strength at the end of the month. The $V$ component velocity shows a similar pattern of bursts of northward flow at the beginning of December 2000 and March 2001, but its phase leads $U$ by about half a month.

Similar to Fig. 2, Fig. 3 shows $U$ and $V$ of lowpass filtered velocity at location E. Significant intraseasonal variations are also evidenced at E. Flow is generally toward southeast except in January and after mid-March. Strong eastward flow appears in mid-October 2000, late November 2000 and late February 2001 when current speeds reach more than $50 \mathrm{~cm} \mathrm{~s}^{-1}$. Two periods of weak westward currents are present in January and middle March 2001. The strong eastward flow is accompanied by strong southward flow in $V$ as shown in the bottom panel. The stick plots of depth averaged velocity at $\mathrm{W}$ $(20-130 \mathrm{~m})$ and $\mathrm{E}(20-180 \mathrm{~m})$ are shown in Fig. 4. Bursts of northeastward flow at $\mathrm{W}$ and those of 
$\mathrm{U}(\mathrm{cm} / \mathrm{s})$

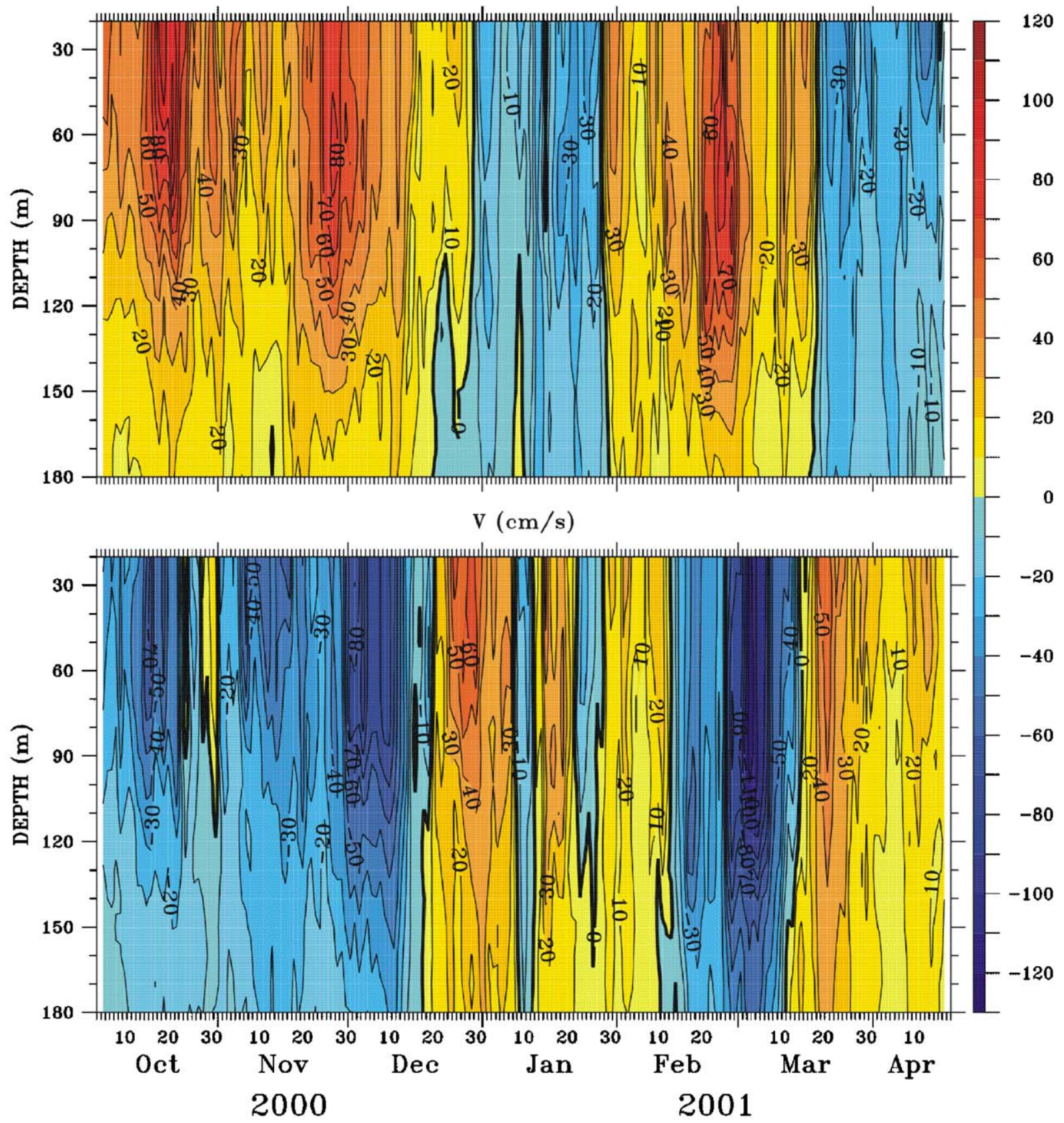

Fig. 3. Same as Fig. 2, except at E.

southeastward flow at E seem to correlate well with changes at $\mathrm{E}$ lead those at $\mathrm{W}$ around 10-15 days. The phenomenon deserves to further verify and will be examined in detail later in the next section.

In Fig. 4, northward flow prevails at $\mathrm{W}$ and southeastward flow exists at $\mathrm{E}$ prior to the middle of December 2000. The feature infers that this region is dominated by a conceptual clockwise circulation pattern. Currents at $\mathrm{W}$ reverse southwestward and meanwhile currents at $\mathrm{E}$ turn either northwestward or northeastward during the period from middle December to middle February. The reversal phenomena suggest that current pattern alters from clockwise circulation to counterclockwise in the 


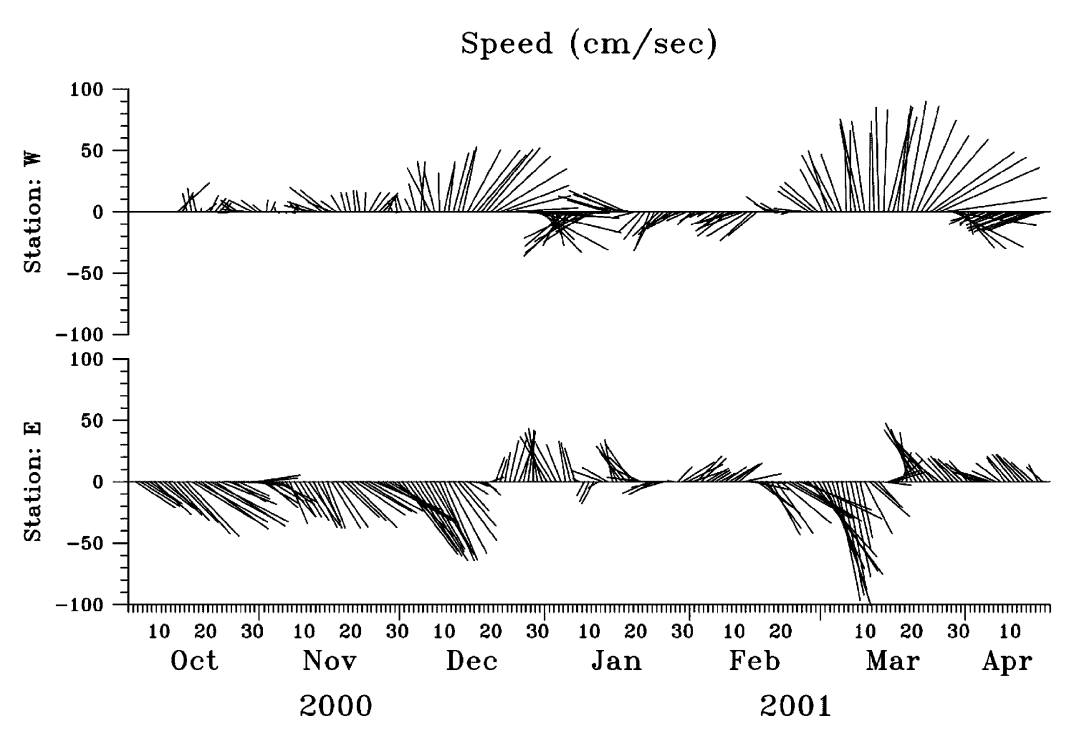

Fig. 4. Stick plots of the depth-averaged current velocity at $\mathrm{W}$ and $\mathrm{E}$, respectively.

study region. Clockwise circulation dominates again during the period from middle February to middle March. Note that the currents are always stronger during clockwise circulation. After March, weak counterclockwise circulation plays the finale. Furthermore, as mentioned in the introduction, currents perform an anticyclone or a cyclone might directly influence the geographic distribution of the water masses in the region. Without a correct description of circulation pattern, it is not possible to identify the water masses and to verify the intrusion process.

\subsection{Water masses and circulation pattern}

To describe the distribution of various water masses and the path of Kuroshio intrusion, the mooring CTD data at both $\mathrm{W}$ and $\mathrm{E}$ were plotted in Fig. 5. Also they join with velocity vectors to separate different episodes of clockwise and counterclockwise circulation. In the figure, the red color represents circulation pattern is clockwise while the blue represents there is counterclockwise circulation. Temperature and salinity of $\mathrm{W}$ and $\mathrm{E}$ were measured at depth of around 160 and $205 \mathrm{~m}$, respectively. Although the absolute values of CTD data are probably problematic, the relative value can still be applied to identify where the water masses come from. Since not only temperature but salinity of $\mathrm{E}$ are generally lower than those of $\mathrm{W}$, the measured depth at $\mathrm{E}$ is deeper could not account for the phenomena singly. Rather, there must be colder and fresher water entering and mixing with the local water around regions of E. Based on longterm mooring observations around sea southwest of Taiwan, mean current always flows southeastward during winter (Chern, 1982). With mixing cold and fresh coastal water from Taiwan Strait, it makes sense that temperature and salinity at $\mathrm{E}$ should be lower than those at W.

Furthermore, concerning the temporal variability in each station, both stations show that temperature is higher whenever clockwise circulation dominates in the region. The temperature contrast is more distinct at $\mathrm{W}$ than that at $\mathrm{E}$; the latter location is affected by cold coastal water (Fig. 5). The higher values of temperature were presented during two periods in December 2000 and in March 2001. The results are reasonable and can be explained by water movement. Currents generally intensify while clockwise circulation performs as mentioned earlier so that stronger intrusion current brings in warmer water from Kuroshio front and then increases water temperature at $\mathrm{W}$. On the other hand, during counterclockwise circulation episode (e.g. in the middle of January), the current is weak and flows westward continuously along its northern boundary in Taiwan Strait. By gradually mixing with cold front from Taiwan Strait, the water temperature decreases.

To further study alternation of circulation pattern and relation between $\mathrm{W}$ and $\mathrm{E}$, we rotated the 
St. W

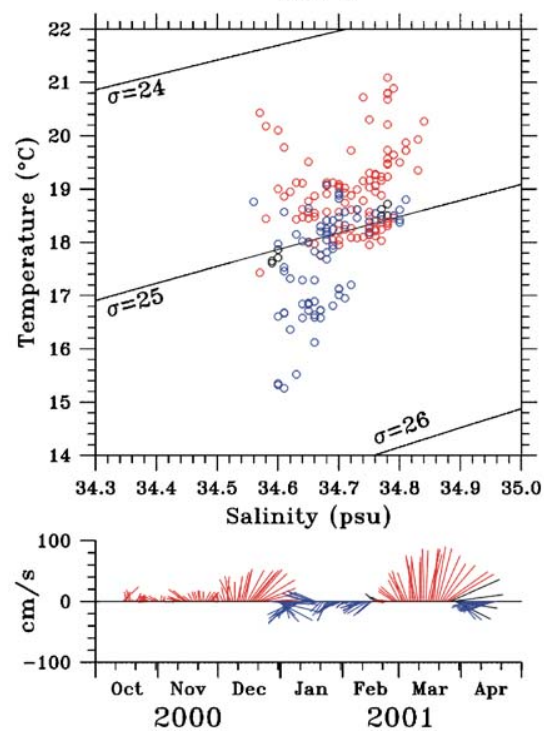

St. E
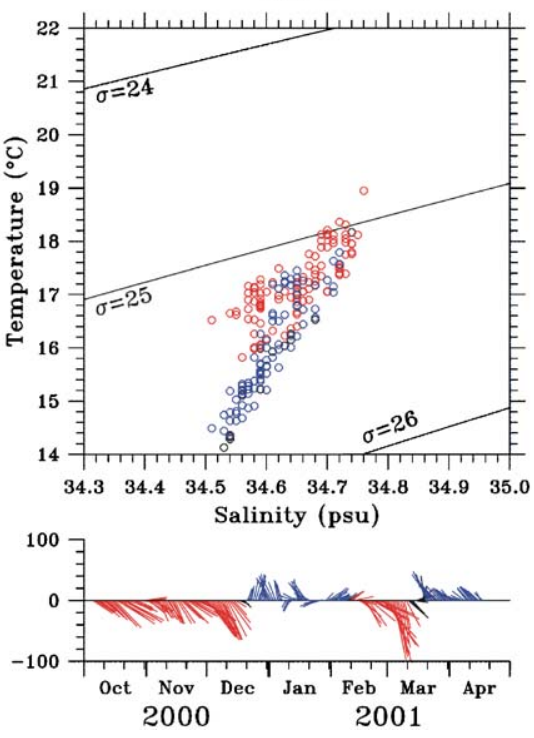

Fig. 5. T-S diagram at W and E. Velocity vectors are also presented to separate different episodes of clockwise (red) and counterclockwise (blue) circulation.

current velocity to its principal axis. The principal axis of $\mathrm{W}$ is $45^{\circ}$ clockwise-rotated Cartesian (northeast-southwest) and $\mathrm{E}$ is $135^{\circ}$ clockwise-rotated Cartesian (southeast-northwest). Figs. 6a and 6b show time series of principal axis depth-average current velocity at $\mathrm{W}$ and $\mathrm{E}$, respectively. Graphically, both $\mathrm{W}$ and $\mathrm{E}$ evidence two significant peaks. However, the timing is not consistent with each other. Two peaks at $\mathrm{W}$ are during the periods December and March while at $\mathrm{E}$ are from middle November to middle December and from middle February to middle March. The results demonstrate that $\mathrm{E}$ leads $\mathrm{W}$ and an interval of $315 \mathrm{~h}$ might properly describe time lag of W. In Fig. 6c, E with a time lag of $315 \mathrm{~h}$ is overlapped to W. Peak to peak comparison indicates that the variations of $\mathrm{W}$ and those in time lag of $\mathrm{E}$ are frequently in phase, suggesting $\mathrm{E}$ leads $\mathrm{W}$ by $10-15 \mathrm{~d}$ indeed. The corresponding advection velocity is around $0.12-0.18 \mathrm{~m} \mathrm{~s}^{-1}$ which is the same order of the propagation speed of a baroclinic Rossby wave in the area $\left(\sim 0.1 \mathrm{~m} \mathrm{~s}^{-1}\right)$. However, the region is not only with complex topography but also bounded in the east by the Taiwan Island. The limited observations cannot describe how a baroclinc Rossby wave propagates in the study region. More observations or numerical modeling efforts are needed for further investigation. The trend that $\mathrm{E}$ leads $\mathrm{W}$ by $10-15 \mathrm{~d}$ is always valid whether it is during episode of clockwise or counterclockwise circulation. The fact that $\mathrm{E}$ leads $\mathrm{W}$ during clockwise episode is probably against intuitive. The two stations might not be located in the same anticyclonic structure.

\subsection{Mechanism}

What causes the intra-seasonal variation in the area deserves further investigation. Intuitively, currents in this area, especially those near the surface, should be driven by the strong monsoon during winter when northeasterly winds prevail. However, there is almost no correlation between the current and local wind forcing from weather station at Tung-Chi Island (figure not shown). On the other hand, the relation of the wind stress curl and the Kuroshio intrusion at the South China Sea has been investigated by Metzger and Hurlburt (1996, 2001). Also, based on model simulations in the South China Sea, Wu et al. (1998) suggested that the formation of a gyre, whether anticyclonic or cyclonic, is determined by the wind stress curl. Shaw et al. (1999) also found that the first two empirical orthogonal functions (EOF) modes of the wind stress curl agree well with those in the corresponding altimeter sea level modes, further supporting the wind stress curl forcing scenario. However, it is not clear whether the wind stress curl is important to meso-scale circulation as in the 

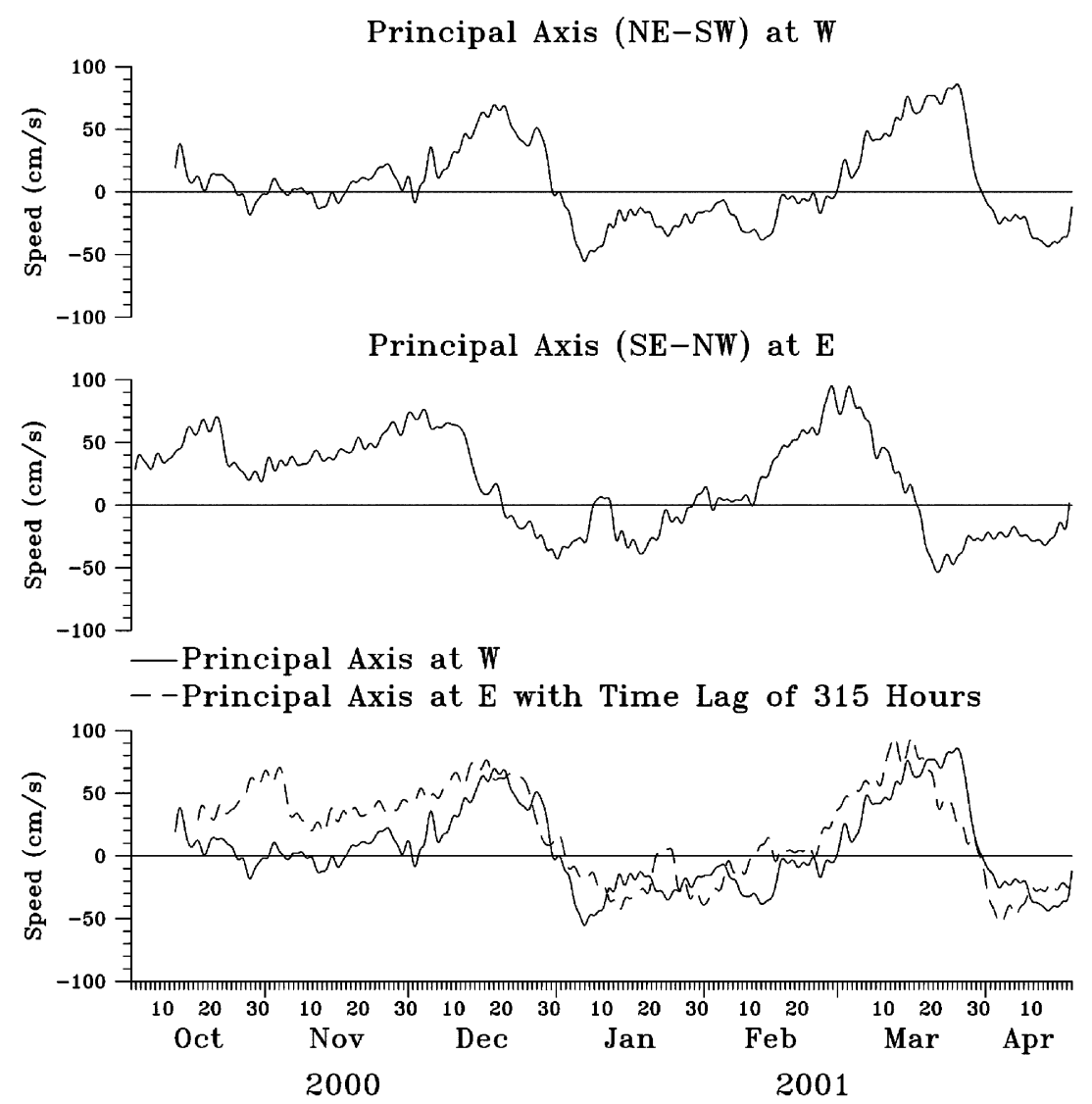

Fig. 6. Time series of principal axis depth-average current velocity at $\mathrm{W}$ and $\mathrm{E}$, respectively. E with time lag of $315 \mathrm{~h}$ is overlapped to $\mathrm{W}$ shown in the bottom panel as well.

present study. Since the scale is quite small in the present study, high-resolution winds are needed. We adopted 6-hourly maps of $10 \mathrm{~m}$ zonal and meridional wind components at a resolution of $0.5^{\circ} \times 0.5^{\circ}$, which is derived from a space and time blend of QSCAT-DIRTH satellite scatterometer observations and NCEP analyses (Milliff et al., 1999). The blended data set is one of the most up-to-date highresolution data of ocean surface winds in the present time.

In this section, wind stress curls are calculated from the blended wind stress fields. Fig. 7 shows the monthly mean of the wind stress curl during the 6month period. The days in February and March 2001 have been slightly adjusted to fit the intraseasonal variation in the velocity field. Main features in the intra-seasonal variation of the wind stress curl are captured in the sequence of plots from (a)-(f). In October 2000 (Fig. 7a), a dipole structure with positive values to the north appeared in the region. Note that the south portion is what we should be more concerned about since its position approaches the Kuroshio intrusion. Off the southern tip of Taiwan, the large and negative curl extends southwestward in October that marks the onset of the winter monsoon. The pattern persists well into November, gradually increasing its strength in December. In the following month, the southern pattern weakens (Fig. 7d). The curl increases again and reaches its maximum strength during the period from February 10 to March 10 (Fig. 7e) and decays afterwards (Fig. 7f).

The variations of the southern pattern are corresponding to those shown in the velocity field and the curl is capable of explaining the intraseasonal variations in the velocity field. While the southern pattern appeared and developed in the position, the intruded current from Kuroshio would form anticyclonic eddies clockwise because the curl provides negative vorticities to the current. Note 


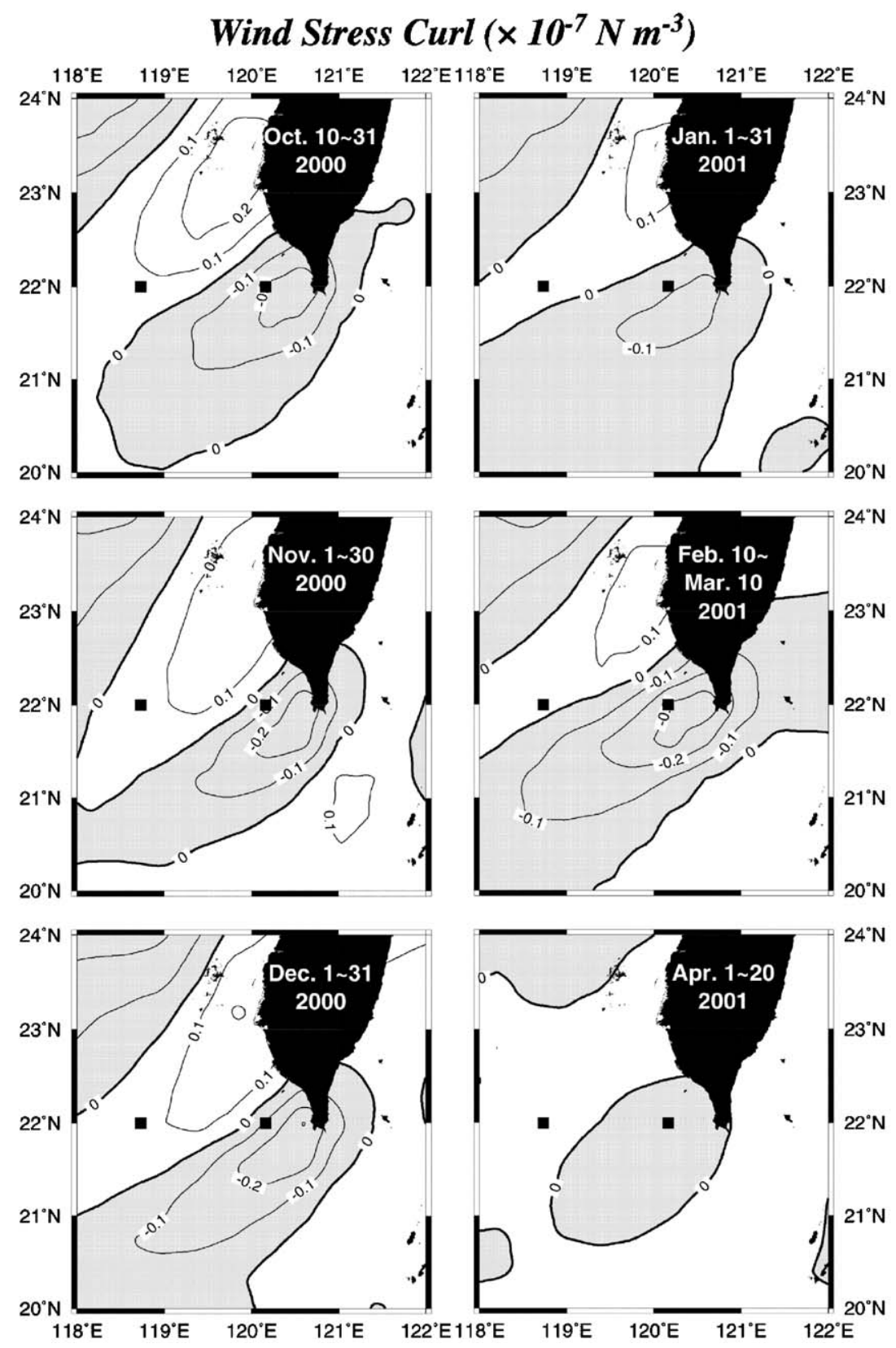

Fig. 7. Monthly mean of the wind stress curl during the six-month period. Contour interval is $0.1 \times 10^{-7} \mathrm{~N} \mathrm{~m}^{-3}$. Regions of negative curls are shaded.

that the strongest southern pattern is confined and limited near E. Therefore, a tight and stronger anticyclone might occur in close vicinity of $\mathrm{E}$ merely. The loose clockwise vortexes might shed away from E while the corresponding Reynolds number is large enough. The large value of curl also explains part of the reason why the current is accelerated during clockwise circulation dominated episode as mentioned earlier. For example, the strongest southward current at E with maximum speed of $100 \mathrm{~cm} \mathrm{~s}^{-1}$ shown on March 1, 2001 is well corresponding to the strongest southern pattern in Fig. 7e. Although the wind stress curl is not energetic enough to give rise to a $100 \mathrm{~cm} \mathrm{~s}^{-1}$ current, the well consistency between the wind stress curls and the observational currents still imply that the 
curls might be one of the major factors to trigger the currents. As shown in Centurioni et al. (2004) that near surface velocities are well below the observed drifter speeds, the strong currents would be the baroclinic currents associated with the density gradients within the Kuroshio. On the other hand, while the southern pattern weakens or loosens (Figs. 7d, 7f), the intruded current overwhelms the curl and continues westward along the shelf break, forming a weak cyclonic (counterclockwise) eddy. Weaker currents in these two counterclockwise episodes are also noted in the previous section.

\section{Summary and conclusions}

Although the East Asian monsoons dominate, an intra-seasonal instead of seasonal variation in the velocity field has been found in the region. The well consistency between wind stress curls and observed velocity fields suggests that the curls could be one of the major factors to trigger the intra-seasonal variations. The intensity of wind stress curl off southern tip of Taiwan might determine whether clockwise or counterclockwise circulation pattern performs in the region. While the southern pattern enhanced, the intruded current strengthens by getting large vorticity from the curl and forms an anticyclonic eddy afterwards. The mooring velocity data indeed evidence that currents during clockwise circulation are much stronger than those during counterclockwise. Temperature is also higher while it is clockwise since the stronger intrusion current will bring in Kuroshio warmer water and increase local water temperature.

\section{Acknowledgements}

Gracious thanks are extended to Drs. Y.J. Yang and W.-D. Liang at Chinese Naval Academy for useful discussions and Mr. Y. C. Tsai for processing the mooring data. The invaluable comments given by two reviewers greatly improved both the presentation and discussion. This research was supported by the National Science Council, Taiwan, ROC, under Grants NSC 92-2611-M-003-004 (CRW) and NSC 89-2611-M-002-031-OP2 (TYT).

\section{References}

Centurioni, L.R., Niiler, P.P., Lee, D.-K., 2004. Observations of inflow of Philippine Sea surface water into the South China Sea through the Luzon Strait. Journal of Physical Oceanography 34, 113-121.

Chern, C.S., 1982. Current and wave measurement in the vicinity of Hsien-Da-Kang and Tung- Kang (continued). Institution of Oceanography, National Taiwan University, Taiwan (Special publication 39).

Liang, W.-D., Tang, T.Y., Yang, Y.J., Ko, M.T., Chuang, W.-S., 2003. Upper-ocean current around Taiwan. Deep-Sea Research II 50, 1085-1105.

Metzger, E.J., Hurlburt, H.E., 1996. Coupled dynamics of the South China Sea, the Sulu Sea, and the Pacific Ocean. Journal of Geophysical Research 101, 12331-12352.

Metzger, E.J., Hurlburt, H.E., 2001. The nondeterministic nature of Kuroshio penetration and eddy shedding in the South China Sea. Journal of Physical Oceanography 31, 1712-1732.

Milliff, R.F., Large, W.G., Morzel, J., Danabasoglu, G., Chin, T.M., 1999. Ocean general circulation model sensitivity to forcing from scatterometer winds. Journal of Geophysical Research 104, 11337-11358.

Nitani, H., Beginning of the Kuroshio, In: Kuroshio, 1972. University of Washington Press, Seattle, Washington. pp. 129-163.

Shaw, P.-T., 1989. The intrusion of water masses into the sea southwest of Taiwan. Journal of Geophysical Research 94, 18213-18226.

Shaw, P.-T., 1991. The seasonal variation of the intrusion of the Philippine Sea water into the South China Sea. Journal of Geophysical Research 96, 821-827.

Shaw, P.-T., Chao, S.-Y., Fu, L.-L., 1999. Sea surface height variations in the South China Sea from satellite altimetry. Oceanologica Acta 22, 1-17.

Wang, J., Chern, C.S., 1987. The warm-core eddy in the northern South China Sea, Preliminary observations on the warm-core eddy. Acta Oceanographica Taiwanica 18, 92-103.

Wu, C.-R., Shaw, P.-T., Chao, S.-Y., 1998. Seasonal and interannual variations in the velocity field of the South China Sea. Journal of Oceanography 54, 361-372.

Wyrtki, K., 1961. Physical oceanography of the southeast Asian waters, Scientific Results of Marine Investigation of the South China Sea and the Gulf of Thailand, NAGA report, Vol. 2 Scripps Institution of Oceanography, La Jolla, CA, p. 195 